\title{
T lymphocytes isolated from patients with advanced colorectal cancer are suitable for gene immunotherapy approaches
}

\author{
AJ Sheen ${ }^{1,2}$, DJ Sherlock', J Irlam', RE Hawkins*,' and DE Gilham' \\ 'Cancer Research UK Department of Medical Oncology, Paterson Institute for Cancer Research, Christie Hospital NHS Trust, University of Manchester, \\ Wilmslow Road, Manchester M20 4BX, UK; ²Department of Surgery, North Manchester Healthcare NHS Trust, Manchester M8 5RB, UK
}

\begin{abstract}
Despite improvements in treatment, the 5-year survival for metastatic colorectal cancer remains poor. Novel approaches such as gene immunotherapy are being investigated to improve treatment. Retroviral gene transfer methods have been shown to transduce primary human $T$ lymphocytes effectively resulting in the expression of therapeutic genes. However, a number of defects have been identified in T lymphocytes isolated from patients bearing tumour, which may have critical implications for the development of genetargeted $T$ cells as an anticancer therapy. To address this issue, primary $T$ lymphocytes were isolated from patients with advanced colorectal cancer and tested for their ability to be transduced and to express subsequently a chimeric immune receptor consisting of a single-chain antibody fragment antigen-binding moiety specific for carcinoembryonic antigen (CEA) fused to the $T$ cell receptor (TCR) CD3 $\zeta$ chain. In 10 out of 10 patients, T lymphocytes were transduced, expanded in the absence of selection and tested for functional activity against CEA-expressing tumour cells. In each case, functional-specific cytotoxic activity was observed. Negligible activity was found in control cultures. This study highlights the feasibility of patient-derived T lymphocytes as a source of immune cells for autologous gene immunotherapy approaches.

British Journal of Cancer (2003) 88, I| |9- I I27. doi: I0.1038/sj.bjc.6600857 www.bjcancer.com
\end{abstract}

(C) 2003 Cancer Research UK

Keywords: T lymphocyte; patient; tumour; retrovirus; chimeric; receptor

Colorectal cancer affects approximately 300000 people in Europe and the US each year (Midgley and Kerr, 1999), accounting for 20-30000 deaths in the UK alone (Curley and Vecchio, 1998). Surgery can cure selected patients with liver metastases (DeMatteo et al, 2000; Biasco and Gallerani, 2001). However, despite continued advances in systemic treatment, the overall 5-year survival has not improved significantly for advanced colorectal disease (Midgley and Kerr, 1999).

Our aim is to utilise the power of the immune system as a novel form of cancer therapy. Gene therapy techniques have been developed to modify $\mathrm{T}$ lymphocytes in order to target and lyse colorectal tumour cells through the development of chimeric immune receptors (CIRs) (Hombach et al, 1999; Nolan et al, 1999; Beecham et al, 2000; Daly et al, 2000). CIRs are composed of antigen binding domains, usually derived from single-chain antibody fragments (scFv) (Hawkins et al, 1998), fused to the cytosolic domains of important signalling receptors (Gross et al, 1989) (Figure 1A). Our present work has focused upon the targeting of carcinoembryonic antigen (CEA) through a CEAspecific scFv fused to the $\mathrm{CD} 3 \zeta$ chain. $\mathrm{CD} 3 \zeta$ is thought to play the predominant role in T-cell signalling resulting in T-cell effector activity (Haynes et al, 2001). Binding of CEA by the CEA-specific CIR generates downstream activation signals resulting in cytokine production and target cell cytotoxicity in the absence of the usual

\footnotetext{
*Correspondence: Professor RE Hawkins;

E-mail: Rhawkins@PICR.man.ac.uk

Received 6 September 2002; revised 27 January 2003; accepted 27 January 2003
}

restrictive mechanisms required for T-cell activation (Hombach et al, 1999; Nolan et al, 1999; Beecham et al, 2000; Daly et al, 2000). This approach results in the generation of large numbers of antigen-specific $\mathrm{T}$ cells. Importantly, since the CIRs recognise whole-protein antigens, tumour cells should not be able to avoid immune detection by the downregulation of immunoregulatory molecules such as major histocompatibility (MHC) molecules.

The CIRs used in this study were either an anti-CEA-specific scFv, MFE23 (derived by phage display technology) (Chester et al, 1994; Begent et al, 1996) or a control scFv (anti-neural cell adhesion molecule (NCAM)) (D29) (Whittington et al, 2001) fused to the human $\mathrm{CD} 3 \zeta$ protein. Both receptors have been shown to be active when introduced into primary human $\mathrm{T}$ lymphocytes derived from healthy donors (Gilham et al, 2002). Importantly, in $\mathrm{T}$ cells derived from these normal, healthy donors, the presence of soluble CEA did not inhibit the cytolytic activity of the genemodified $\mathrm{T}$ lymphocytes suggesting that high-serum CEA should not interfere with the activity of the anti-CEA CIR in patients.

However, important questions remain concerning the viability of this approach for clinical use. A number of studies have demonstrated that $\mathrm{T}$ lymphocytes isolated from tumour-bearing mice (Mizoguchi et al, 1992) and patients (Bukowski et al, 1998) are dysfunctional owing to altered expression of key proteins including members of the CD3 complex. T lymphocytes isolated from patients with advanced melanoma (Saito et al, 2000), and head and neck cancer (Hoffman et al, 2002) have also been shown to be more susceptible to spontaneous apoptosis thereby potentially compromising the patient's own immune competence. Furthermore, tumour-infiltrating lymphocytes isolated from 
A

\begin{tabular}{|c|c|}
\hline scFv & Target \\
\hline MFE23 & $\begin{array}{c}\text { Carcinoembryonic } \\
\text { antigen (CEA) }\end{array}$ \\
\hline D29 & $\begin{array}{c}\text { Neural cell adhesion } \\
\text { molecule (NCAM) }\end{array}$ \\
\hline Mock & No target \\
\hline
\end{tabular}

B

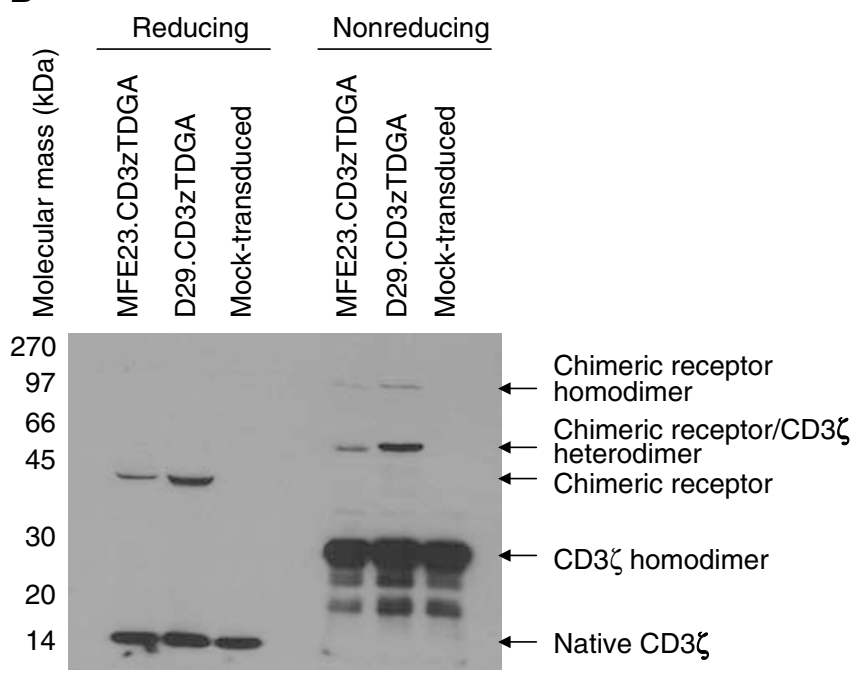

Figure I Expression of chimeric receptor proteins in primary human $T$ lymphocytes derived from patients with advanced colorectal cancer. (A) The specificity of the scFv used in these studies. (B) Chimeric receptor transduced and mock patient $T$ lymphocytes, at time of cytotoxicity assays, were lysed with RIPA and subjected to reducing or nonreducing SDSPAGE and transferred to nitrocellulose filters. Blots were probed with antiCD3 $\zeta$ Mab (I : I 000 dilution, Pharmingen, Oxford, UK) with a secondary antibody of anti-mouse Fc-HRP conjugate $(1: 2000)$ and immunoreactive bands visualised using $\mathrm{ECL}^{\mathrm{TM}}$ (Amersham, UK). Under reducing conditions, the endogenous $\mathrm{CD} 3 \zeta$ protein was identified as a $16 \mathrm{kDa}$ band in all samples with the chimeric receptors clearly identified as single immunoreactive bands at the predicted molecular mass of $43 \mathrm{kDa}$. Chimeric homodimers $(86 \mathrm{kDa})$ and heterodimers $(60 \mathrm{kDa})$ formed with the endogenous $\mathrm{CD} 3 \zeta$ were identified along with $\mathrm{CD} 3 \zeta$ homodimers (32 $\mathrm{kDa}$ ) under nonreducing conditions.

colorectal hepatic metastases have been shown to have reduced $\mathrm{CD} 3 \zeta$ chain expression and, upon expansion, lack tumour-specific lytic activity (Yoong and Adams, 1998). In view of this work and to further determine the viability of our approach in a clinical setting, $\mathrm{T}$ lymphocytes were isolated from the peripheral blood of patients with advanced colorectal disease (hepatic colorectal metastases) in order to determine whether they could be efficiently gene modified to express a chimeric immune receptor. Subsequently, the functional activity of the CIR in T lymphocytes was assessed through its ability to induce cytolytic activity when challenged with tumour cell lines in vitro.

\section{MATERIALS AND METHODS}

\section{Reagents}

All chemical reagents except where stated were purchased from Sigma (Dorset, UK). Anti-CD3e (OKT3) was purchased from
Orthobiotech (USA) and anti-hCD28 from R\&D Systems (Minneapolis, MN, USA). Chiron (Amsterdam, The Netherlands) supplied the recombinant human IL-2.

\section{Cell culture}

All cell culture materials were obtained from Life Sciences (Paisley, Scotland). The human CEA-positive cell lines MKN45 K (human gastric carcinoma, kindly provided by Dr J Embleton, PICR), LS174T (human colon adenocarcinoma, ECACC No. 87060401), LoVo (human colon adenocarcinoma, ECACC No. 87060101), NCAM positive SK-N-BE (human neuroblastoma, ATCC No. CCRL-2271), PG13 retroviral producer cells (Miller et al, 1991) and HeLa (human cervix epithelial carcinoma, ECACC No. 93021013) cell lines were all cultured in Dulbecco's modified Eagle's medium (DMEM) with $10 \%$ foetal bovine serum (FBS, Life Technologies, Paisley, Scotland). Patient $\mathrm{T}$ lymphocytes were cultured in T-cell media (RPMI 1640, $25 \mathrm{~mm}$ HEPES, $2 \mathrm{~mm}$ glutamine and $5 \times 10^{5}$ 2-mercaptoethanol with the addition of $10 \%$ FBS). All cells were maintained in a $37^{\circ} \mathrm{C} 5 \% \mathrm{CO}_{2} /$ air incubator.

\section{Production of recombinant receptors encoding CIRs}

Stable PG13 cell lines producing either rkat.MFE23.CD3 $\zeta$ TDGA.IRES.EGFP and rkat.D29.CD3 $\zeta$ TDGA.IRES.EGFP recombinant retroviruses have been previously described (Gilham et al, 2002). These vectors consist of the MFE23 scFv (specific for CEA) or the D29 $\mathrm{scFv}$ (specific for NCAM) fused to the $\mathrm{CD} 3 \zeta$ receptor protein with the enhanced green fluorescent protein (EGFP) coexpressed by means of an internal ribosome entry site (IRES) element. Cell culture media were aspirated from PG13 cell monolayers (approximately $70-80 \%$ confluent) and replaced with T-cell media. Retrovirus was collected after an overnight incubation and then filtered through a $0.45 \mu \mathrm{m}$ filter prior to its use in transduction. T-cell media were replaced onto the PG13 monolayer with more virus collected and filtered after an overnight incubation for second and subsequent transductions.

\section{Patient details}

All patients selected were due to undergo hepatic resection for colorectal liver metastases and were consented for the purposes of this study as approved by North and South Manchester Ethics committees. The median age of the patients was 66 years (range $42-73$ years, mean $65.2 \pm 9.9$ years). No patient had received any form of chemotherapy for at least 1 month prior to T lymphocyte harvest. Preoperative serum CEA levels and operations performed are listed in Table 1.

\section{Patient T lymphocyte isolation and transduction}

Approximately $20 \mathrm{ml}$ of venous blood was obtained from each patient approximately $2-3$ weeks prior to hepatic resection. Heparinised venous blood was diluted 1:1 ratio with serum-free RPMI 1640 media and mononuclear cells isolated by Ficoll-density gradient centrifugation (Ficoll-Histopaque (density $1077 \mathrm{gl}^{-1}$ ) Sigma, Dorset, UK). Monocytes were depleted by adherence to plastic by culture for $1 \mathrm{~h}$ in tissue culture flasks at $37^{\circ} \mathrm{C}$. Nonadherent lymphocytes were isolated and activated in 6-well nontissue culture plates precoated antibody (OKT-3 and antiCD28) with $100 \mathrm{IU} \mathrm{ml}^{-1}$ interleukin-2 (IL-2) for at least 3 days. After activation, $\mathrm{T}$ lymphocytes were ficolled to remove dead cells, washed and counted. $1-4.5 \times 10^{6} \mathrm{~T}$ lymphocytes were mixed with PG13-derived retroviral supernatant and polybrene $\left(6 \mu \mathrm{g} \mathrm{ml}^{-1}\right)$ in a $50 \mathrm{ml}$ falcon tube and centrifuged for $2-3 \mathrm{~h}$ at $1400 \times \mathrm{g}$. Mock-transduced cells were mixed with T-cell media with polybrene instead of retroviral supernatant and centrifuged. After 
Table I A summary of patient details, including operation and preoperative serum CEA levels, with T lymphocyte population phenotypes after retroviral transduction and expansion

\begin{tabular}{|c|c|c|c|c|c|c|c|c|c|}
\hline $\begin{array}{l}\text { Patient } \\
\text { (age in years) }\end{array}$ & $\begin{array}{l}\text { ScFv fused to } \\
\text { CD3 } \zeta \text { TDGA }\end{array}$ & $\begin{array}{l}\text { Preoperative } \\
\text { CEA }\left(\mu \mathrm{gI}^{-1}\right)\end{array}$ & Operation & $\%$ CD3+ & $\begin{array}{c}\text { \% CD3+, } \\
\text { GFP+ }\end{array}$ & $\begin{array}{c}\text { \% CD8+, } \\
\text { GFP+ }\end{array}$ & $\begin{array}{l}\text { \% CD4+, } \\
\text { GFP+ }\end{array}$ & $\begin{array}{c}\text { Ratio of } \\
\text { transduced } \\
\text { CD8+ : CD4+ }\end{array}$ & $\begin{array}{c}\text { Ratio of } \\
\text { total } \\
\text { CD8+ : CD4+ } \\
\text { T cells }\end{array}$ \\
\hline \multirow[t]{3}{*}{ I (70) } & Mock & 35 & Left hepatectomy & 99 & 0 & 0 & 0 & - & $11.5: 1$ \\
\hline & MFE23 & & & 99 & 20 & 12 & 3 & $4: 1$ & $8.9: 1$ \\
\hline & D29 & & & 99 & 15 & 17 & 3 & $5.7: 1$ & $9.1: 1$ \\
\hline $2(66)$ & Mock & 6 & Right hepatectomy & 99 & 0 & 0 & 0 & - & $4.2: 1$ \\
\hline \multirow[t]{3}{*}{$3(64)$} & Mock & I & Right hepatectomy & 96 & I & 0 & 0 & - & $2.3: 1$ \\
\hline & MFE23 & & & 91 & 21 & 19 & 16 & $1.2: 1$ & $1.5: 1$ \\
\hline & D29 & & & 90 & 13 & 9 & 6 & $1.2: 1$ & $1.5: 1$ \\
\hline \multirow{3}{*}{$4(70)$} & Mock & 9 & Right hepatectomy & 99 & 0 & 0 & 0 & - & $1.9: 1$ \\
\hline & MFE23 & & & 94 & 21 & 19 & 8 & $2.4: 1$ & $2.1: 1$ \\
\hline & D29 & & & 97 & 9 & 11 & 5 & $2.2: 1$ & $2.2: 1$ \\
\hline $5(42)$ & Mock & 155 & $\begin{array}{l}\text { Left hepatectomy } \\
\quad+\text { segmentectomy }\end{array}$ & 88 & 1 & 2 & I & $2: 1$ & $1.3: 1$ \\
\hline \multirow{2}{*}{$6(73)$} & MFE23 & & & 88 & 11 & 10 & 1.5 & $6.7: 1$ & $4.3: 1$ \\
\hline & D29 & & & 87 & 4 & 5 & I & $5: 1$ & $7.6: 1$ \\
\hline \multirow[t]{3}{*}{7 (78) } & Mock & 6 & $\begin{array}{l}\text { Inoperable - extra-hepatic } \\
\text { disease }\end{array}$ & 99 & 0 & 0 & 0 & - & $1.9: 1$ \\
\hline & MFE23 & & & 99 & 23.9 & 15.6 & 7.9 & $2: 1$ & ।.8: | \\
\hline & D29 & & & 99 & 2 & 1 & 0.3 & $3.3: 1$ & |.8: 1 \\
\hline \multirow[t]{3}{*}{$8(66)$} & Mock & 4 & $\begin{array}{l}\text { Inoperable - extra-hepatic } \\
\text { disease }\end{array}$ & 99 & 0 & 0 & 0 & - & $8.8: 1$ \\
\hline & MFE23 & & & 99 & 19.9 & 15.5 & 1.9 & $8.1: 1$ & $7.0: 1$ \\
\hline & D29 & & & 99 & 2 & 1.3 & 0.2 & $6.5: 1$ & $8.4: 1$ \\
\hline \multirow[t]{3}{*}{$9(66)$} & Mock & 24 & Right hepatectomy & 99 & 0 & 0 & 0 & - & $7.4: 1$ \\
\hline & MFE23 & & & 99 & 25 & 17 & 3 & $5.7: 1$ & $8.5: 1$ \\
\hline & D29 & & & 99 & 20 & 19 & 2 & $9.5: 1$ & $8.2: 1$ \\
\hline $10(57)$ & Mock & 156 & Left hepatectomy & 99 & 2 & 0 & 0 & - & $4.2: 1$ \\
\hline
\end{tabular}

All 10 patients recruited were due to undergo surgery for colorectal hepatic metastases. All the metastases removed or biopsed were confirmed as adenocarcinoma of colorectal origin by histological examination. T lymphocytes were isolated from these patients $2-3$ weeks prior to surgery and were transduced with recombinant retroviruses encoding either MFE23.CD3 expression of the EGFP marker gene and for the surface markers CD3, CD4 and CD8 by staining with PE-conjugated antibodies and subsequent flow cytometric analysis using a FACscan (Becton Dickenson) with winMDI software.

centrifugation, $\mathrm{T}$ lymphocytes were cultured overnight at $5 \times 10^{5} \mathrm{ml}$ with $100 \mathrm{IU} \mathrm{ml}^{-1}$ IL-2. Centrifugal transduction was repeated the next day and the resulting cell populations were maintained at $5 \times 10^{5}$ cells ml $^{-1}$ in $100 \mathrm{IU} \mathrm{ml}^{-1} \mathrm{IL}-2$. Fresh media and IL-2 were added every $2-3$ days.

\section{Flow cytometry}

Cells were washed with phosphate-buffered solution (PBS)/2\% bovine serum albumin (BSA) and then resuspended in saturating concentrations of antibody (anti-CD3e, CD4, CD8 and suitable isotype controls (all R-Phycoerythrin conjugated) purchased from Pharmingen, Oxford, UK) on ice for $30 \mathrm{~min}$. Cells were then washed twice with $\mathrm{PBS} / 2 \%$ BSA, fixed in $2 \%$ paraformaldehyde and analysed using a FACscan (Becton Dickenson, CA, USA) with winMDI version 2.8 analysis software.

\section{Cytotoxicity assays}

Three days prior to cytotoxicity assay, $\mathrm{T}$ lymphocytes were cultured in low IL-2 $\left(20 \mathrm{IU} \mathrm{ml}^{-1}\right)$ to reduce background lymphokine-activated killer (LAK) activity (Gilham et al, 2002). An 8-h chromium release assay was performed as previously described (Gilham et al, 2002) with effector:target ratios from 50:1 to $6.25: 1$. Maximal release was obtained by coculture with $100 \mu \mathrm{l} 2 \%$ Triton X-100/PBS and spontaneous release by target cell culture in media alone. Percentage-specific lysis was determined by the following formula:

$$
\frac{(\text { observed release }- \text { spontaneous release })}{(\text { maximum release }- \text { spontaneous release })} \times 100
$$

\section{Western blotting}

Patient $\mathrm{T}$ lymphocytes were washed with PBS and lysed in RIPA buffer (150 mM NaCl, 1\% NP-40, 0.5\% deoxycholic acid, $0.5 \%$ sodium dodecyl sulphate (SDS) and $50 \mathrm{~mm}$ Tris- $\mathrm{Cl} \mathrm{pH} 8.0$ ) at the time of cytotoxicity assay and stored at $-70^{\circ} \mathrm{C}$. Approximately $5 \times 10^{5}$ cells were separated by standard techniques using SDS/PAGE on 10\% resolving gels (Lamelli, 1970). Hybond ${ }^{\mathrm{TM}}$ $\mathrm{ECL}^{\mathrm{TM}}$ nitrocellulose membrane (Amersham Pharmacia Biotech, Buckinghamshire, UK) was used for blots with anti-CD3 $\zeta$ (clone 8D3) at 1:1000 dilution (Pharmingen, Oxford, UK) and a secondary of sheep anti-mouse HRP antibody at 1:2000 
dilution (Sigma, Dorset, UK). Visualisation was performed using $\mathrm{ECL}^{\mathrm{TM}}$ reagents (Amersham Pharmacia Biotech, Buckinghamshire, UK).

\section{Tumour cell survival assay}

Adherent tumour target cell lines (MKN45 K, LS174 T, LoVo and HeLa) were plated at a density of 5000 cells in $100 \mu$ l of $\mathrm{T}$ cell media per well of flat-bottomed 96 -well plates. These cells were allowed to adhere for $3 \mathrm{~h}$ at which point a further $100 \mu \mathrm{l}$ of T-cell media containing either varying numbers of transduced or control $\mathrm{T}$ lymphocytes or culture medium alone was added to the target cells to generate a final volume of $200 \mu \mathrm{l}$. In some experiments, IL-2 was added to a final concentration of $100 \mathrm{IU} \mathrm{ml}^{-1}$. After a period of coculture, the supernatant containing nonadherent cells was removed and the remaining cells cultured in DMEM with $10 \%$ FBS without IL-2 for a further 5-6 days. The culture medium was aspirated, the cells washed once with PBS and $100 \mu$ l of DMEM with $10 \%$ FBS containing a 40 -fold dilution of Wst-1 reagent (Roche, Surrey, UK). At suitable time points, the optical density of the wells was determined using an ELISA plate reader (Molecular Devices, Sunnydale, CA, USA) set at 450-650 nm. Maximal cell growth was determined from the optical density reading of tumour cells cultured without $\mathrm{T}$ lymphocytes and minimal cell growth was determined from tumour cells cultured without $\mathrm{T}$ lymphocytes and lysed with $50 \mu \mathrm{l}$ of $2 \%$ Triton X-100/PBS. Relative tumour cell growth was estimated by the following equation:

$$
\frac{(\text { test cell growth OD }- \text { minimal cell growth OD })}{(\text { maximal growth OD }- \text { minimal cell growth OD })} \times 100
$$

\section{RESULTS}

\section{Transduction of patient $\mathrm{T}$ lymphocytes}

Twenty millilitres of venous blood was obtained from patients 1 to 10 two to three weeks prior to the date of surgery. $\mathrm{T}$ lymphocytes were isolated and activated using immobilised anti-CD3 and antiCD28 antibodies. After 3 days of antibody activation, 5-10 $\times 10^{6}$ viable $\mathrm{T}$ cells were counted by trypan blue exclusion for each patient indicating that in 10 out of 10 samples, $\mathrm{T}$ lymphocytes were successfully activated. Transduction with retroviruses encoding the anti-CEA CIR, MFE23.CD3 TDGA or the anti-NCAM CIR, D29.CD3 $\zeta$ TDGA (Figure 1A) was performed using centrifugation in the presence of polybrene. After transduction, patient $\mathrm{T}$ lymphocytes were expanded in number by $5-10$-fold over the next 7-21 days in the presence of $100 \mathrm{IU} \mathrm{ml}^{-1}$ of IL-2 (data not shown). Flow cytometry analysis confirmed the cell populations to consist largely of CD3-positive T lymphocytes (87-99\%, Table 1). The IL-2-based expansion protocol supported the growth of the polyclonal $\mathrm{T}$ lymphocyte populations, although there was a relative predominance of $\mathrm{CD} 8+$ over $\mathrm{CD} 4+\mathrm{T}$ cells. The lowest ratio of CD8 : CD4 was $1.5: 1$, while ratios in excess of $10: 1$ were recorded for two donors.

The level of retroviral transduction was estimated through the expression of the EGFP marker gene. A degree of heterogeneity was also observed with the levels of retroviral transduction varying between 2 and 33\% (Table 1). In each patient sample, the ratio of transduced CD8 to transduced CD4 cells reflected the overall ratio of total CD8 to CD4 $\mathrm{T}$ cells in the total population suggesting there to be little bias in the susceptibility of either T-cell sub-type to transduction by the PG13-derived retroviruses.

Chimeric immune receptor expression in $\mathrm{T}$ lymphocytes was confirmed by Western blotting (Figure 1B). Nonreducing Western blots identified the formation of CIR homodimers and also heterodimers formed between the CIR and wild-type $\mathrm{CD} 3 \zeta$. Reducing Western blots demonstrated an immunoreactive band at the predicted molecular mass of the CIR $(43 \mathrm{kDa})$ with the native $\mathrm{CD} 3 \zeta$ protein present as a $16 \mathrm{kDa}$ immunoreactive band.

\section{Specific cytotoxicity of CEA-positive cells by patient- modified T lymphocytes}

MFE23.CD3 $\zeta$ TDGA-modified lymphocytes from patient 1 demonstrated specific cytotoxic activity against the CEA-expressing gastric tumour cell line MKN45 $\mathrm{K}$ and the colon adenocarcinoma LS174T cell line. Negligible cytotoxicity was observed when NCAM-targeted (D29.CD3 $\zeta$ TDGA) and mock-transduced T lymphocytes were cocultured with the MKN45 K or LS174 T cell lines (Figures 2A and B). Specific CEA-targeted lysis was found to be increased by at least seven-fold over that of nontargeted lymphocytes.

The specificity of cell killing was confirmed by the cytotoxic activity of D29.CD3 $\zeta$ TDGA-transduced $\mathrm{T}$ lymphocytes against NCAM-positive neuroblastoma SK-N-BE target cells (Figure 2C). In this case, low background activity was found when CEAtargeted (MFE23.CD3\%TDGA) and mock-transduced T lymphocytes were cultured with CEA-negative SK-N-BE cells (Figure 2C). HeLa cells (NCAM- and CEA-negative) were used to demonstrate equivalent nonspecific killing by all three populations thereby confirming that the specific killing observed was because of CIR activity and not because of any altered killing properties of the individual lymphocyte populations (Figure 2D). The level of retroviral transduction (as assessed by the expression of EGFP) was $20 \%$ in the MFE23.CD3 $\zeta$ TDGA CIR-expressing population generated from patient 1 . This figure indicates that the maximal transduced effector to target ratio was $10: 1$ with highly specific cytolytic activity observed down to a ratio of 1.25 transduced effector cells per target (Figure 2A). In the case of NCAM-targeted cells (SK-N-BE, Figure 2C), the proportion of D29.CD3 לTDGAexpressing cells was estimated to be $15 \%$, hence, the transduced effector to target ratio was maximally 7.5:1 with clear specific cytolytic activity at the lowest ratio tested ( 0.9 transduced $\mathrm{T}$ cells per target cell).

Specific, targeted cytotoxicity was subsequently demonstrated for the remaining five patient lymphocyte samples against MKN45 K gastric carcinoma cells (Figure 3). In each case, specific, dose-dependent killing was observed. Furthermore, in each case, very low background levels of killing were observed (D29.CD3 $\zeta$ TDGA and mock-transduced lymphocytes). This probably reflects the period of preculture in low concentrations of IL-2 reducing nonspecific cytokine-mediated killing activity. Equivalent specific lysis was observed between the various transduced cell populations when tested against CEA-negative, NCAM-negative target cells indicating there to be no difference in the overall killing activity of the modified or nonmodified $\mathrm{T}$ lymphocyte populations (data not shown).

A consideration of the level of retroviral transduction (as assessed by EGFP expression) did not appear to provide a clear relation between the levels of expression of the CIRs with the observed CIR-mediated cytotoxic activities. There was maximally a 6.6-fold difference between these six patient samples in retroviral transduction frequency, yet the cytotoxic activity varied only 1.6fold. It was clear that the lowest level of transduction correlated with the weakest cytolytic activity (Patient 2; 5\% CD3+, GFP+; $20.1 \%$ specific killing). However, there appeared little difference in cytolytic activity in these populations once a transduction level of $20 \%$ had been achieved.

\section{Tumour cell survival after coculture with gene-modified T lymphocytes}

Short-term assessments of cytolytic activity clearly demonstrated that CIR-expressing T-cell populations were functional against protein antigen targets in an MHC-independent manner. In an 

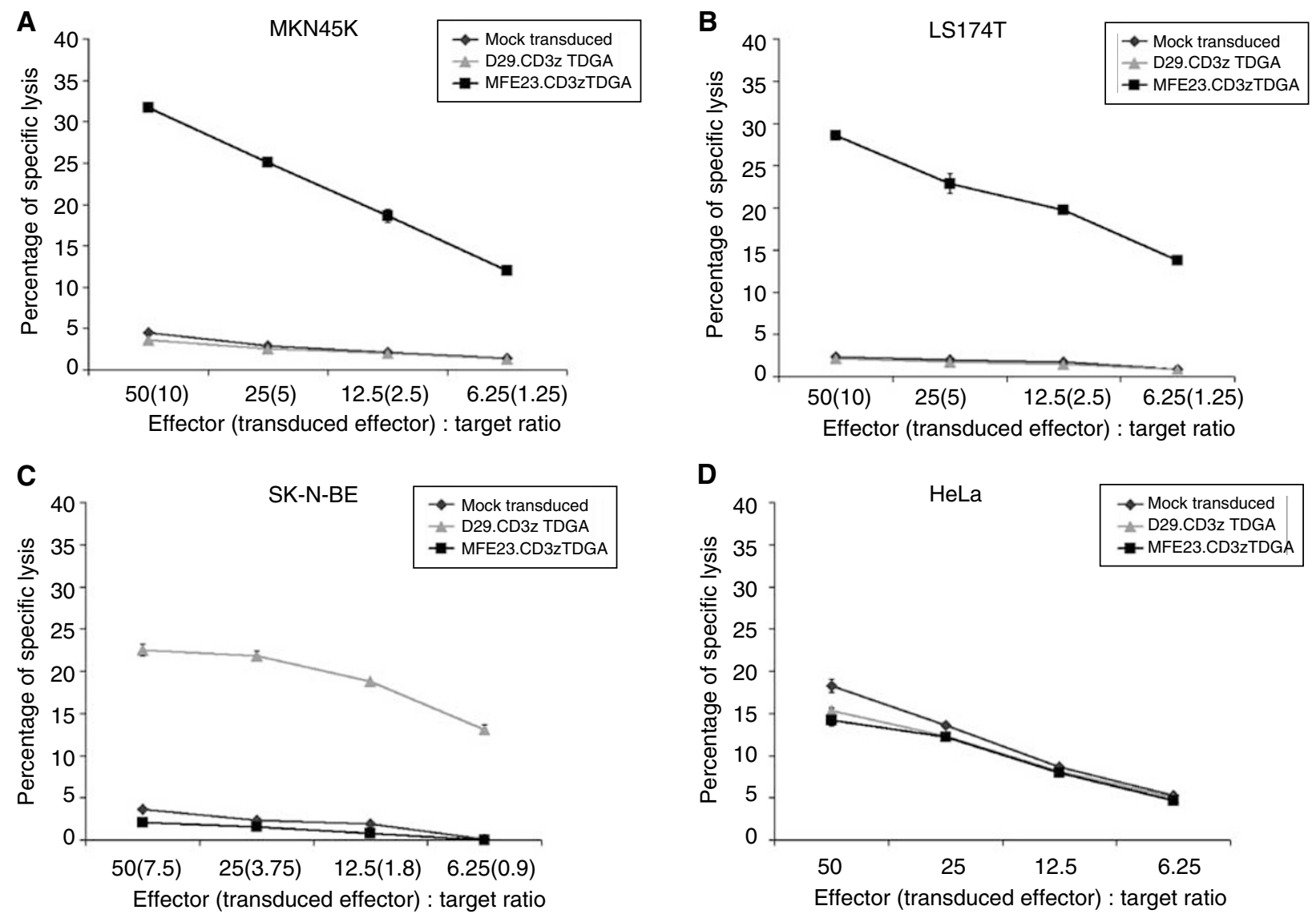

Figure 2 Chimeric receptor-expressing T lymphocyte populations demonstrate antigen-specific killing of tumour cell lines. T lymphocytes derived from

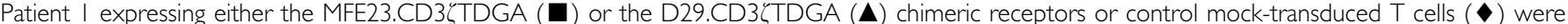
cocultured with $5000{ }^{51} \mathrm{Cr}$-labelled target cells per well at the indicated effector: target ratios. (The transduced effector: target ratio based upon EGFP fluorescence is also presented.) After $8 \mathrm{~h}, 100 \mu \mathrm{l}$ of media was harvested and analysed for released ${ }^{51} \mathrm{Cr}$ label (Topcount, Packard, Berkshire, UK). Maximal lysis was determined by lysis of target cells by 2\% Triton X-I00/PBS. Target cell lines used were MKN45 K (A), LSI74T (B), SK-N-BE (C) and HeLa (D). The results presented are the mean \pm s.d. of triplicate wells.

attempt to investigate and understand the functionality of these gene-modified cell populations further, and in an effort to quantify the overall efficiency of the targeted gene modified cells, longer-term tumour cell survival assays were used to assess the effectiveness of these $\mathrm{T}$ cells. Adherent tumour cell lines were cocultured with nonadherent $\mathrm{T}$ lymphocytes for set periods of time, after which the nonadherent cells were removed and the tumour cells cultured in media without cytokines to ensure that any remaining $\mathrm{T}$ cells would not survive. Five to six days, later, the growth of the tumour cells was assessed using an MTT-based assay (Mosmann, 1983).

Multiple cell lines were used in order to examine the activity of the anti-CEA-targeted $\mathrm{T}$ cells. The CEA-expressing human colon adenocarcinoma lines (LS174 T and LoVo) as well as the gastric carcinoma cell line $(\mathrm{MKN} 45 \mathrm{~K})$ were tested as targets along with HeLa cells used as a control since they do not express CEA. This subsequent work utilised $\mathrm{T}$ lymphocytes generated from four further patients $(7-10$, Table 1$)$. The results depicted in Figure 4 represent the activity of cells generated from Patient 1 0 and are representative of experiments performed with Donors 7-10.

The first observation was that the cell lines used displayed a differential degree of susceptibility to coculture with transduced or control $\mathrm{T}$ lymphocytes. HeLa cells proved to be the most sensitive in that very low levels of target cell survival were recorded when cocultured for $24 \mathrm{~h}$ in the presence of $\mathrm{T}$ cells at an effector: target ratio approaching 1:1 (Figure 4D). However, it was clear that there existed no difference in the sensitivity of HeLa cells to either transduced or nontransduced $\mathrm{T}$ cells, indicating that there was equivalent nonspecific killing activity between the T-cell populations in agreement with the results observed in chromium release assay. The specific effect of T-cell targeting was observed in assays using CEA-expressing tumour cell lines. In each case, tumour cell survival was reduced in a dose-dependent manner when the target cells were cocultured with MFE23.CD3 $\zeta$ TDGA T-cell populations as compared to either NCAM-targeted or control nontransduced $\mathrm{T}$ cells (Figure $4 \mathrm{~A}-\mathrm{C}$ ). There was a clear difference in target cell growth observable at effector: target ratios of $10: 1$, which represented a transduced effector: target ratio of $1.4: 1$. However, only at the highest cell dose ( $80: 1$ total cells, 11.2:1 transduced effector:target ratio) there was no tumour cell growth observed by all three target cell lines after a 24 -h period of coculture. The susceptibility of the gastric (MKN45 K) and adenocarcinoma (LoVo and LS174 T) cell lines to nonspecific killing was reduced compared to that of HeLa cells. However, in the case of LoVo and LS174 T cells, the highest dose of nontargeted control $\mathrm{T}$ cells resulted in a reduction in target cell survival to levels approximately $40 \%$ of maximal (Figures $4 \mathrm{~A}$ and $\mathrm{C}$ ). For MKN45 $\mathrm{K}$ target cells, there appeared to be an equivalent degree of antitumour activity in targeted 


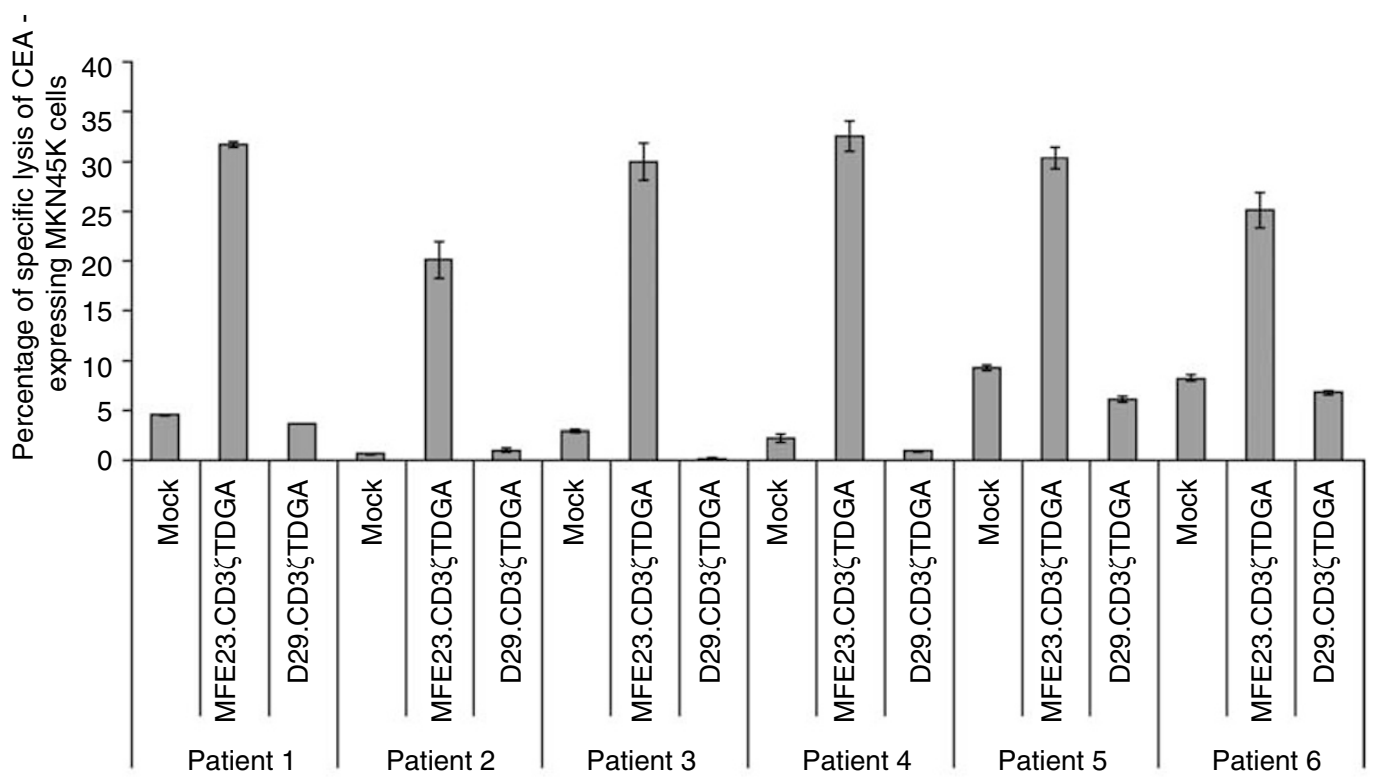

Figure 3 Antigen-specific cytotoxicity mediated by chimeric receptor expressing $T$ lymphocytes generated from five patients with advanced colorectal cancer. A summary of the cytotoxic activity of T-cell populations generated from Patients I to 6 expressing either the MFE23.CD3 $\zeta$ TDGA or the D29.CD3 $\zeta$ TDGA chimeric receptors or control, mock-transduced T cells. Standard 8-h chromium release assay was performed using MKN45 K gastric carcinoma cells as targets with the T-cell effectors at an effector: target ratio of 50 : I. The results presented are the mean \pm s.d. of triplicate wells.

(MFE23.CD3 $\zeta$ TDGA) and nontargeted (D29.CD3 $\zeta$ TDGA and mock-transduced $\mathrm{T}$ cells) at the maximum dose of effector cells (Figure 4B). Microscopic examination of the culture wells confirmed that large adherent tumour cells were present in the wells identified as having metabolic activity within the assay with few lymphocytic cells present. This indicated that attached lymphocytes made a minimal contribution to the metabolic activity of the wells in agreement to similar assays performed elsewhere (Hombach et al, 2001).

The inclusion of IL-2 during the period of coculture drastically enhanced the effectiveness of target cell killing. For control HeLa cell targets, a maximal repression of target cell growth was observed at an effector : target ratio of 20:1 compared to a ratio of $80: 1$ required in the absence of this cytokine. Once again, there was little difference between the effectiveness of each T-cell population in repressing HeLa cell growth (Figure $4 \mathrm{H}$ ). A similar degree of enhanced antitumour activity was recorded after coculture of CEA-expressing cell lines with the T-cell populations. Maximal tumour cell growth repression was found at lower doses of effector cells than in the absence of IL-2. Total repression was found at effector:target ratios of $20: 1$ (2.8 transduced MFE23.CD3 (TDGA cells : 1 target) for both LS174 T and MKN45 K cells, while the low dose of 2.5:1 (0.4 transduced cells per effector target) resulted in maximal LoVo cell killing. The specificity of activity was maintained with a clear difference in the cytolytic activity of targeted and nontargeted (NCAM and mock-transduced cells) being evident (Figures $4 \mathrm{E}-\mathrm{G}$ ). However, enhanced nonspecific, cytokine-driven killing activity was observed against each cell line since a total repression of tumour cell growth occurred at lower effector doses than that observed in the absence of IL-2.

\section{DISCUSSION}

Recent studies have shown that $\mathrm{T}$ lymphocytes can be redirected against cancer cell lines using CEA as a target antigen through the use of CIRs expressed in $\mathrm{T}$ cells isolated from healthy donors (Nolan et al, 1999; Beecham et al, 2000; Daly et al, 2000; Hombach et al, 2000). In our study, the chimeric receptor consisted of an extracellular antigen-binding domain ( $\mathrm{scFv}$ ) specific for CEA (Chester et al, 1994; Begent et al, 1996), attached to the CD3 $\zeta$ component of the T-cell receptor complex. This CIR has already been demonstrated to be effective in initiating cytokine secretion and the cytotoxic activities of normal donor $\mathrm{T}$ lymphocytes (Gilham et al, 2002).

In the light of published work demonstrating the dysfunctional properties of $\mathrm{T}$ lymphocytes isolated from patients with a cancer load (Rosenberg et al, 1994; Bukowski et al, 1998; Yoong and Adams, 1998), the aims of this project were to assess whether the conditions used to activate and transduce $\mathrm{T}$ lymphocytes from normal donors were equally effective in $\mathrm{T}$ lymphocytes from patients with advanced colorectal cancer. In addition, it is important to evaluate whether CIR crosslinking in the presence of antigen would generate a response in patient cells similar to that of normal donors.

Ten patients with advanced colorectal cancer were recruited into this study. T lymphocytes were successfully transduced with efficiencies ranging from 2 to $33 \%$ (mean $15 \pm 9 \%, n=20$ ) for all viruses and from 5 to $33 \%$ (mean $19.4 \pm 7.8 \%$ ) for MFE23.CD3/TDGA-transduced T cells (Table 1). It is clear that higher levels of transduction are preferable particularly with respect to use in a clinical context. Protocols have been developed that have reported high-level gene transfer using longer antibody-mediated preactivation periods (Movassagh et al, 2000), through the use of retronectin to enhance infection (Hanenberg et al, 1996) or by preloading plates with retrovirus (Kuhlcke et al, 2002). The levels of retroviral transduction generated here represent those achieved using a short period of centrifugation (spin-fection) and is adaptable to transduction on a large scale. An over-riding issue concerns the development of such protocols into a clinically applicable process using good manufacturing process (GMP) guidelines. Clinical trials using chimeric receptor expressing $\mathrm{T}$ lymphocytes against HIV (Mitsuyasu et al, 2000) and current trials using plasmid- 


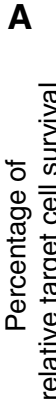

Cells cultured in the absence of IL-2

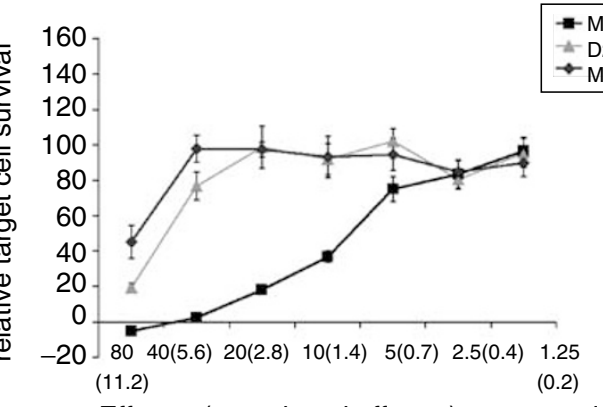

Effector (transduced effector) : target ratio

B

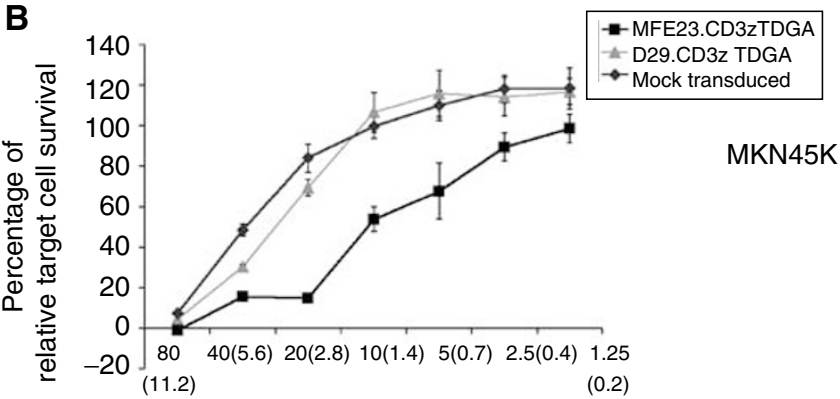

Effector (transduced effector) : target ratio

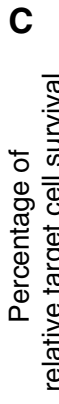

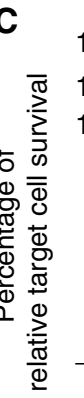

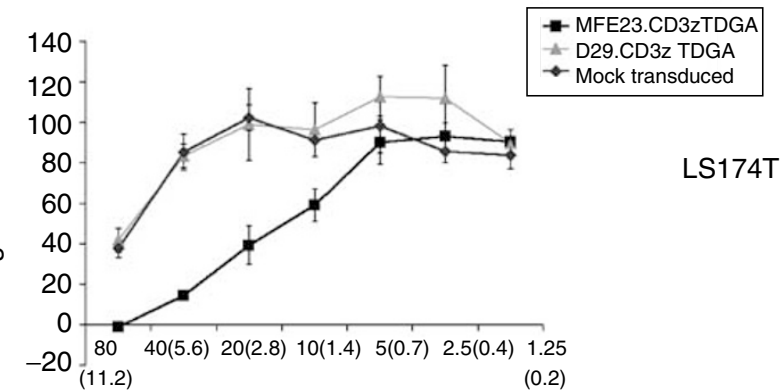

Effector (transduced effector) : target ratio

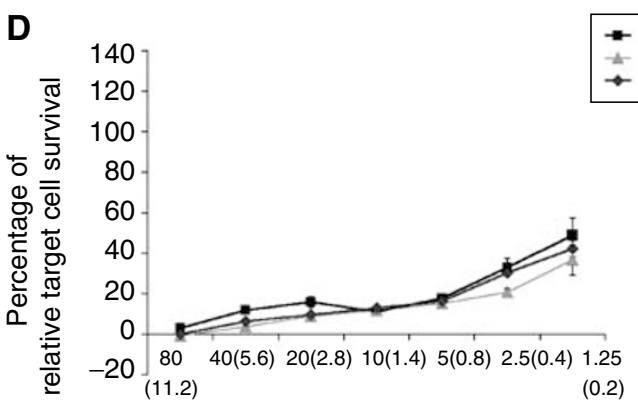

Effector (transduced effector) : target ratio
E
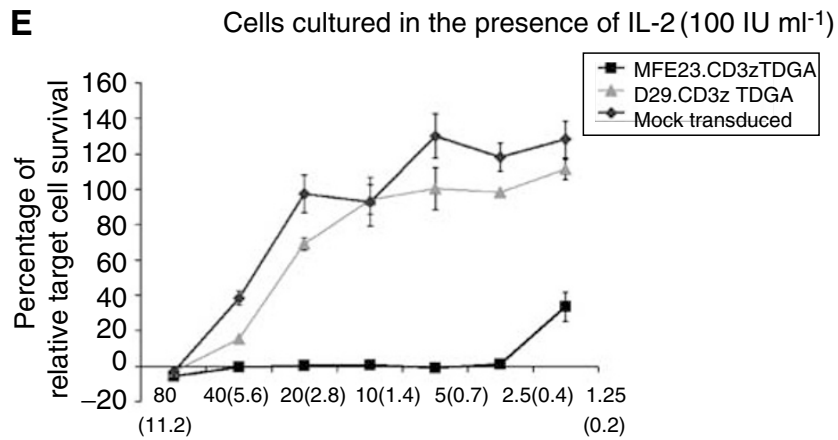

Effector (transduced effector) : target ratio

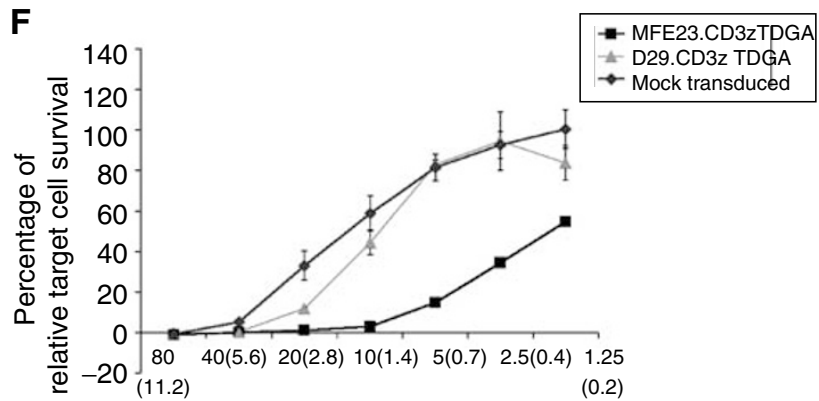

Effector (transduced effector) : target ratio

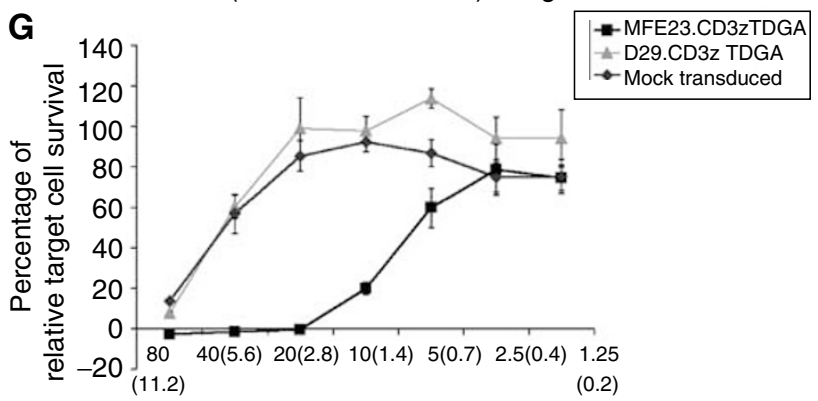

Effector (transduced effector) : target ratio

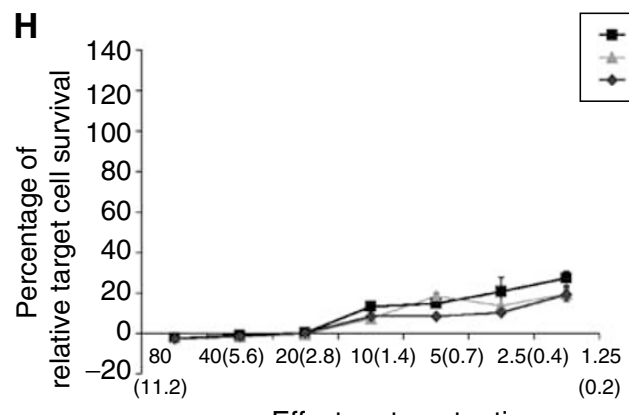

Effector : target ratio

Figure 4 Tumour target cell survival after coculture with targeted and nontargeted T lymphocytes. Adherent tumour cell lines (5000) were cultured with

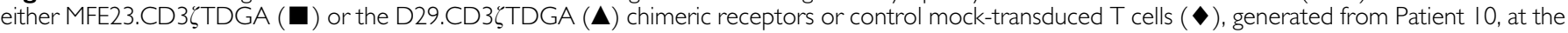
indicated effector: target ratios (The transduced effector: target ratio based upon EGFP fluorescence is also presented.) in wells of flat-bottomed 96-well plates in a final volume of $200 \mu \mathrm{l}$. Interleukin-2 was added to some wells at a final concentration of $100 \mathrm{IU} \mathrm{ml}^{-1}(\mathrm{E}-\mathrm{H})$. After $24 \mathrm{~h}$, media and nonadherent cells were removed and replaced with target cell culture medium without T-cell cytokines. After a further 5 days of culture, the wells were aspirated, washed with PBS and I00 $\mu \mathrm{l}$ of DMEM/I0\% FBS containing a 1:40 dilution of wst-I reagent (Roche, Surrey, UK). The optical density of the wells was assessed at 450-650 nm using an ELISA plate reader (Molecular Devices, Sunnydale, CA, USA). Maximal tumour cell growth was assessed from the optical density of wells containing tumour cells only and minimal growth determined from wells containing tumour cells lysed with $2 \%$ Triton X-I00. Target cell lines used were MKN45 K (A), LSI74T (B), SK-N-BE $(\mathbf{C})$ and HeLa (D). The results are presented as the mean \pm s.d. values of quadruplicate wells.

transfected $\mathrm{T}$ cells expressing chimeric receptors (Jensen et al, 2000) have demonstrated the feasibility of this approach, and efficient gene-transfer protocols are now being developed based upon this experience. As a result, the optimal protocol may or may not feature some of the methods described above. As such, the use of a spin-fection protocol permitted levels of transduction that were suitable to permit the analysis of CIR activity in primary patient T cells. 
After transduction, all 10 of the patient T-cell samples were expanded using an IL-2-based expansion protocols. The level of expansion reported here using IL-2 alone ranged from five- to 10fold above the starting number. For clinical application, an ideal scenario would involve the generation of large numbers of $\mathrm{T}$ cells from, for example, a single blood collection or leucophoresis. It would be anticipated that a larger scale expansion of patientderived lymphocytes would be required. Preliminary studies have shown that the inclusion of soluble antibodies (OKT3 and antiCD28) with IL-2 enhanced the level of expansion above that with IL-2 alone (data not shown). These experiments have used standard media with FBS and, as such, do not represent conditions proposed for use in a clinical situation. Our efforts are now directed to investigating the growth of patient-derived $\mathrm{T}$ lymphocytes using GMP conditions reported for the maximal growth of $\mathrm{T}$ lymphocytes elsewhere (Carlens et al, 2000). However, the fact that all 10 patient samples were successfully transduced and expanded was encouraging, considering the reported frailties of patientderived T lymphocytes (Mizoguchi et al, 1992; Rosenberg et al, 1994; Bukowski et al, 1998).

The CIR-bearing cell populations responded to antigen present on cell lines through specific target cell lysis in an MHCindependent manner. Importantly, even in the T-cell population with the lowest transduction level, significant antigen-specific cytotoxic activity was observed. Interestingly, increasing the level of retroviral transduction did not result in an increasing functional cytotoxic activity. Once a transduction level of $20 \%$ had been achieved, there appeared to be little increase in overall antigenspecific cytotoxicity as assessed by chromium release assay. These observations, albeit on a restricted number of transduced patient samples, indicates that more complicated factors may be at work. Further work is required to determine whether the killing activity generated by the transduced population is mediated by a few modified cells acting with high efficiency or whether the majority of CIR-expressing cells are acting at lower efficiency in order to generate the antigen-specific cytotoxicity observed here. This is important because further development of this approach may require optimisation of the receptor in order to produce a stronger response in cells where killing efficiency is low, while a modification to T-cell activation and culture conditions may be required to generate a greater number of highly cytotoxic $\mathrm{T}$ cells.

Interestingly, the specific production of interferon gamma from the T-cell cultures in the presence of antigen was less clearcut. Although there was evidence of specific cytokine production from some donors, in others there was either high background or poor levels of overall cytokine secretion (data not shown). The reasons for this are unclear, but were not related to cytotoxic activity.

An alternative to the chromium release assay was used to further investigate the potential of the gene-modified $\mathrm{T}$ lymphocytes. Tumour cell survival was assessed after a period of coculture with $\mathrm{T}$ cells. These assays potentially assess the longer-term interactions of effector and target cells, which may affect target cell survival through processes such as the induction of apoptosis through cytokine activity or death receptor activation.

An important observation was the fact that there was a difference in the overall sensitivity of the individual tumour cell lines to coculture with allogeneic $\mathrm{T}$ cells. This feature may be reflected in vivo where tumours would most likely show a variation in susceptibility to T lymphocyte activity. HeLa cells proved to be most sensitive to nonspecific killing in the tumour cell survival assay. In comparison, the colon adenocarcinoma and gastric cell lines were more resistant to nonspecific killing, although these cell lines were efficiently targeted by anti-CEA CIR-expressing Tcell populations. Coculture in the presence of IL-2 drastically enhanced both the nonspecific and specific killing activities of the T-cell populations. A total repression of target cell growth was seen in effector : target ratios as low as 2.8 transduced T cells per target for MKN45 K and LS174 T cells and as low as 0.4 transduced cells per target for LoVo cells. It is not clear whether the enhanced cytolytic activity is through enhanced lymphokine-activated killer (LAK) activity of the $\mathrm{T}$ cells resulting in the $\mathrm{T}$ cells being more active in cytolytic assays or whether the IL-2 was acting as a survival factor effectively enhancing the survival of the $\mathrm{T}$ cells (which had previously been expanded in IL-2), thereby permitting an enhanced killing activity. In either case, it is clear that cytokine help is potentially of crucial importance in the clinical setting through the reduction of the number of $\mathrm{T}$ cells required to target a tumour mass.

From the in vitro data presented here, the addition of IL-2 resulted in at least a four-fold decrease in the cell number required to effect a total repression of tumour cell line growth. It is impossible to apply in vitro assay results directly to the problem of dealing with tumour masses in vivo. However, this work suggests that for CIR-expressing $\mathrm{T}$ lymphocytes to function in a practical form in vivo, the CIR-modified cells will require some help in the form of survival or activation signals. These signals may take the form of infusions of IL-2. However, IL-2 administration is associated with toxicity. Alternative studies in our own group have investigated the ability of antiapoptotic genes to act as survival factors which could be expressed from a single retroviral construct (Eaton et al, 2002). Recent developments in CIRs have also involved the generation of receptors composed of the CD3 $\zeta$ domain fused to the CD28 receptor signalling chain (Hombach et al, 2001; Maher et al, 2002). These fusion receptors generate both a cytotoxic response and a costimulatory signal (and therefore IL-2 production) in an attempt to more closely mimic the events that naturally occur when $\mathrm{T}$ cells encounter antigenproducing cells in order to produce an effective immune response.

Our data indicate that $\mathrm{T}$ lymphocytes derived from patients with advanced colorectal cancer are able to mount effective, MHCindependent, functional responses after transduction with CIRencoding recombinant retroviruses. Other studies have shown that T lymphocytes isolated from patients with ovarian (Parker et al, 2000) and prostate (Gong et al, 1999) cancers are also susceptible to retroviral transduction and CIR-mediated functional activity. These studies together demonstrate that patient-derived $\mathrm{T}$ lymphocytes are indeed suitable as vehicles for this type of gene modification and that CIR technology is highly flexible through the use of antibody recognition enabling virtually any protein antigen to be targeted by $\mathrm{T}$ lymphocytes. However, it is also clear from this work that a further understanding of $\mathrm{CD} 3 \zeta$-based CIR activities and aspects of manipulated T lymphocyte biology, particularly with respect to their function in vivo and the development of practical GMP-based handling methods, are required to ensure that this approach is fully adapted for clinical trial.

\section{ACKNOWLEDGEMENTS}

AJS was supported by HALT (Help Against Liver Tumours, a registered Charity No. 1054556) and Cancer Research UK. DEG, JI and REH were supported by Cancer Research UK. We acknowledge the support of The Neuroblastoma Society and the assistance of A O'Neill with the retroviral vector constructions, N Kirillova with the initial $\mathrm{T}$ lymphocyte work and $\mathrm{Dr} \mathrm{R}$ Guest for their valuable contributions. 


\section{REFERENCES}

Beecham E, Ortiz-Pujols S, Junghans R (2000) Dynamics of tumour cell killing by human $\mathrm{T}$ lymphocytes armed with an anti-carcinoembryonic antigen chimeric immunoglobulin $\mathrm{T}$-cell receptor. I Immunother 23: $332-343$

Begent R, Verhaar M, Chester K, Casey J, Green AJ Napier M, Hope-Stone L, Cushen N, Keep P, Johnson C, Hawkins R, Hilson A, Robson L (1996) Single-chain Fv antibody selected from a combinatorial library: clinical evidence of efficient tumour targeting. Nat Med 2: 979-984

Biasco G, Gallerani E (2001) Treatment of liver metastases from colorectal cancer: what is the best approach today? Dig Liver Dis 33: 438-444

Bukowski RM, Rayman P, Uzzo R, Bloom T, Sandstrom K, Peereboom D, Olencki T, Budd GT, McLain D, Elson P, Novick A, Finke JH (1998) Signal transduction abnormalities in $\mathrm{T}$ lymphocytes from patients with advanced renal carcinoma: clinical relevance and effects of cytokine therapy. Clin Cancer Res 4: 2337-2347

Carlens S, Gilljam M, Remberger M, Aschan J, Christensson B, Sirac Dilber M (2000) Ex vivo T lymphocyte expansion for retroviral transduction: Influence of serum-free media on variations in cell expansion rates and lymphocyte sub-set distribution. Exp Haematol 28: 1137-1146

Chester K, Begent R, Robson L, Keep P, Pedley R, Boden J, Boxer G, Green A Winter G, Cochet O, Hawkins R (1994) Phage libraries for the generation of clinically useful antibodies. Lancet 343: $455-456$

Curley SA, Vecchio R (1998) New trends in the surgical treatment of colorectal cancer liver metastases. Tumori 84: 281-288

Daly T, Royal RE, Kershaw MH, Treisman J, Wang G, Li W, Herlyn D, Eshhar Z, Hwu P (2000) Recognition of human colon cancer by T cells transduced with a chimeric receptor gene. Cancer Gene Ther 7: $284-291$

DeMatteo RP, Fong Y, Jarnagin WR, Blumgart LH (2000) Recent advances in hepatic resection. Semin Surg Oncol 19: 200-207

Eaton D, Gilham DE, O’Neill A, Hawkins RE (2002) Retroviral transduction of human peripheral blood lymphocytes with $\mathrm{bcl}-\mathrm{x}(\mathrm{L})$ promotes in vitro lymphocyte survival in proapoptotic conditions. Gene Therapy 9: $527-535$

Gilham DE, O’Neil A, Hughes C, Guest RD, Kirillova N, Lehane M, Hawkins R (2002) Primary polyclonal human T lymphocytes targeted to CEA and NCAM tumor antigens by CD3(zeta) based chimeric immune receptors. $J$ Immunother 25: $139-151$

Gong M, Latouche J, Krause A, Heston W, Brander N, Sadelain M (1999) Cancer patient $\mathrm{T}$ cells genetically targeted to prostate-specific membrane antigen specifically lyse prostate cancer cells and release cytokines in response to prostate-specific membrane antigen. Neoplasia 1: $123-127$

Gross G, Waks T, Eshhar Z (1989) Expression of immunoglobulin-T-cell receptor chimeric molecules as functional receptors with antibody-type specificity. Proc Nat Acad Sci USA 86: 10024-10028

Hanenberg H, Xiao X, Dilloo D, Hashino K, Kato I, Williams D (1996) Colocalization of retrovirus and target cells on specific fibronectin fragments increases genetic transduction of mammalian cells. Nat Med 2: $876-882$

Hawkins RE, Whittington HA, Watkins SJ, Gilham DE (1998) Antibodies: from genes to targeted cancer gene therapy. Gene Therapy 5: 1581-1583

Haynes NM, Snook MB, Trapani JA, Cerruti L, Jane SM, Smyth MJ, Darcy PK (2001) Redirecting mouse CTL against colon carcinoma: superior signaling efficacy of single-chain variable domain chimeras containing TCR-zeta vs Fc epsilon RI-gamma. J Immunol 166: 182 - 187

Hoffman T, Dworacki G, Tsukihiro T, Meidenbauer N, Gooding W, Johnson J, Whiteside TL (2002) Spontaneous apoptosis of circulating T lymphocytes in patients with head and neck cancer and its clinical importance. Clin Cancer Res 8: 2553-2562

Hombach A, Koch D, Sircar R, Heuser C, Diehl V, Kruis W, Pohl C, Abken $\mathrm{H}$ (1999) A chimeric receptor that selectively targets membrane-bound carcinoembryonic antigen (mCEA) in the presence of soluble CEA. Gene Therapy 6: $300-304$

Hombach A, Schneider C, Sent D, Koch D, Willemsen R, Diehl V, Kruis W, Bolhius R, Pohl C, Abken H (2000) An entirely humanized CD3 $\zeta$-chain signaling receptor that directs peripheral blood $\mathrm{T}$ cells to specific lysis of carcinoembryonic antigen-positive tumour cells. Int J Cancer 88: 115120

Hombach A, Wieczarkowiecz A, Marquardt T, Heuser C, Usai L, Pohl C, Selinger B, Abken H (2001) Tumour-specific $\mathrm{T}$ cell activation by recombinant immunoreceptors: $\mathrm{CD} 3 \zeta$ signaling and $\mathrm{CD} 28$ co-stimulation are simultaneously required for efficient IL-2 secretion and can be integrated into one combined $\mathrm{CD} 28 / \mathrm{CD} 3 \zeta$ signaling receptor molecule. J Immunol 167: 6123-6131

Jensen M, Clarke P, Tan G, Wright C, Chung-Chang W, Clark TN, Zhang F, Slovak ML, Wu AM, Forman SJ, Raubitschek A (2000) Human T lymphocyte genetic modification with naked DNA. Mol Ther 1: 49-55

Kuhlcke K, Fehse B, Schilz A, Loges S, Lindemann C, Ayuk F, Lehmann F, Stute N, Fauser AA, Zander AR, Eckert HG (2002) Highly efficient retroviral gene transfer based on centrifugation-mediated vector preloading of tissue culture vessels. Mol Ther 5: 473-478

Laemmli UK (1970) Cleavage of structural proteins during the assembly of the head of bacteriophage T4. Nature 227: 680-685

Maher J, Brentjens R, Gunset G, Rivere I, Sadelain M (2002) Human T-lymphocyte cytotoxicity and proliferation directed by a single chimeric TCR $/$ /CD28 receptor. Nat Biotechnol 20: $70-75$

Midgley R, Kerr D (1999) Colorectal cancer. Lancet 353: 391 - 399

Miller A, Garcia J, von Suhr N, Lynch C, Wislon C, Eiden M (1991) Construction and properties of retrovirus packaging cells based on Gibbon ape leukemia virus. J Virol 65: 2220-2224

Mitsuyasu R, Anton P, Deeks S, Scaddon D, Connick E, Downs M, Bakker A, Roberts M, June C, Jalali S, Lin A, Pennthur-Das R, Hege K (2000) Prolonged survival and tissue trafficking following adoptive transfer of $\mathrm{CD} 4 \zeta$ gene-modified autologous $\mathrm{CD} 4+$ and $\mathrm{CD} 8+\mathrm{T}$ cells in human immunodeficiency virus-infected subjects. Blood 96: 785-793

Mizoguchi H, O'Shea JJ, Longo DL, Loeffler CM, McVicar DW, Ochoa AC (1992) Alterations in signal transduction molecules in T lymphocytes from tumor-bearing mice. Science 258: $1795-1798$

Mosmann T (1983) Rapid colorimetric assay for cellular growth and survival: application to proliferation and cytotoxicity assays. J Immunol Methods 65: 55-63

Movassagh M, Boyer O, Burland M, Leclercq V, Klatzman D, Lemoine F (2000) Retrovirus-mediated gene transfer into T cells: $95 \%$ transduction efficiency without further in vitro selection. Hum Gene Ther 11: 11891200

Nolan KF, Yun CO, Akamatsu Y, Murphy JC, Leung SO, Beecham EJ, Junghans RP (1999) Bypassing immunization: optimized design of 'designer T cells' against carcinoembryonic antigen (CEA)-expressing tumors, and lack of suppression by soluble CEA. Clin Cancer Res 5: $3928-3941$

Parker LL, Do MT, Westwood JA, Wunderlich JR, Dudley ME, Rosenberg SA, Hwu P (2000) Expansion and characterization of T cells transduced with a chimeric receptor against ovarian cancer. Hum Gene Ther 11: $2377-2387$

Rosenberg S, Yannelli J, Topalian S, Schwartzentruber D, Weber J, Parkinson D, Seipp CA Einhorn J, White D (1994) Treatment of patients with metastatic melanoma with autologous tumour-infiltrating lymphocytes and interleukin-2. J Nat Cancer Inst 86: 1159-1166

Saito T, Dworacki G, Gooding W, Lotze MT, Whiteside TL (2000) Spontaneous apoptosis of CD8 + T lymphocytes in peripheral blood of patients with advanced melanoma. Clin Cancer Res 6: 1351-1364

Whittington HA, Hancock J, Kemshead JT (2001) Generation of a humanised single chain Fv (Scfv) derived from the monoclonal Eric-1 recognising the human neural cell adhesion molecule. Med Pediatr Oncol 36: $243-246$

Yoong KF, Adams DH (1998) Interleukin 2 restores CD3-zeta chain expression but fails to generate tumour-specific lytic activity in tumourinfiltrating lymphocytes derived from human colorectal hepatic metastases. Br J Cancer 77: $1072-1081$ 